\title{
Ancillary data from animal-borne cameras as an ecological survey tool for marine communities
}

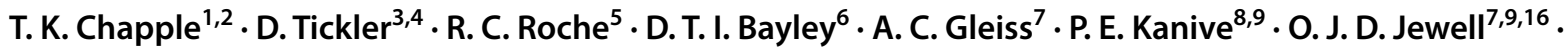 \\ S. J. Jorgensen ${ }^{9,15} \cdot$ R. Schallert ${ }^{2} \cdot$ A. B. Carlisle ${ }^{10} \cdot$ J. Sannassy Pilly ${ }^{5} \cdot$ S. Andrzejaczek ${ }^{2,11} \cdot$ M. Wikelski $^{12,13}$. \\ N. E. Hussey ${ }^{14}$ - B. A. Block ${ }^{2}$
}

Received: 4 July 2020 / Accepted: 18 April 2021 / Published online: 19 June 2021

(c) The Author(s) 2021

\begin{abstract}
Underwater visual surveys represent an essential component of coastal marine research and play a crucial role in supporting the management of marine systems. However, logistical and financial considerations can limit the availability of survey data in some systems. While biologging camera tag devices are being attached to an increasing diversity of marine animals to collect behavioral information about the focal species, the ancillary imagery collected can also be used in analytical techniques developed for diver-based surveys. We illustrate this approach by extracting ancillary data from shark-borne camera tag deployments focused on the behavior of a White shark (Carcharodon carcharias) off Gansbaai, South Africa, and a Grey Reef shark (Carcharhinus amblyrhynchos) within the Chagos Archipelago. Within the giant kelp forest environment of Gansbaai we could determine the spatial density of kelp thali and underlying substrate composition. Within the coral reef environment, the animal-borne video allowed us to determine the approximate percent and type of benthic cover, as well as growth form and genus of corals down to the upper mesophotic zone. We also enumerated fish species-level abundance over reef flat and wall environments. We used established dive-survey methods to analyze video data and found the results to be broadly comparable in the two systems studied. Our work illustrates the broad applicability of ancillary animal-borne video data, which is analogous in type and quality to diver-based video data, for analysis in established marine community survey frameworks. As camera tags and associated biologging technologies continue to develop and are adapted to new environments, utilising these data could have wide-ranging applications and could maximise the overall cost-benefit ratio within biologging deployments.
\end{abstract}

\section{Introduction}

Underwater visual surveys represent an essential component of coastal marine research and play a crucial role in supporting the management of marine systems (Mallet and Pelletier 2014). Diver-based surveys, conducted using underwater visual census (UVC) or diver-operated video systems (DOVs), have been the most commonly used methods for direct, non-destructive observation of marine taxa in neritic environments (Bean et al. 2017; Bayley and Mogg 2019). Novel tools, such as remotely operated and autonomous

Responsible Editor: E. Hunter.

Reviewed by undisclosed experts.

T. K. Chapple

taylor.chapple@oregonstate.edu

Extended author information available on the last page of the article underwater vehicles, baited remote underwater video systems (BRUVS), towed video systems, and mixed-gas closed-circuit rebreathers (Pinheiro et al. 2016), have been developed where survey site characteristics (e.g., extreme depths or low encounter rates with target taxa) make depthand time-limited scientific diver-based surveys impractical (Jones et al. 2009; Rees 2009; Beisiegel et al. 2017). Although together these techniques have led to a rich body of literature, considerations, such as logistics and advanced training needs, can limit their use.

Alongside logistical and training constraints, collection of data in the marine environment is typically both time-consuming and expensive to conduct, which has led many practitioners to aspire to a "Collect once and use many times" principle to increase cost efficiency and avoid duplication of effort (Borja and Elliott 2013). Similarly, this principle of coordinating accurate and multifaceted data collection to avoid duplication of surveys for different purposes, is 
integral to major data collection regulations such as the European Data Collection Framework (Regulation (EU) No 1380/2013). This ambition for greater efficiency is further linked to a focus on potential combinations of tasks and methodologies to fulfill monitoring needs, to increase scale and create comprehensive assessments using often limited resources (Bean et al. 2017).

In light of these data-collection considerations, animalborne sensors have proven to be an effective means to opportunistically collect oceanographic data where logistical factors limit available data (e.g., McMahon et al. 2005; Simmons et al. 2009; Teo et al. 2009; Coffey and Holland 2015). Similarly, ancillary data from camera-enabled biologging tags, developed and deployed to study tagged animals' movement and behavior, may offer a means to expand or complement traditional survey efforts.

Animal-borne video is emerging as a powerful tool to gather direct observations on the behavior of focal study species, but the video data collected can also capture observations of sympatric species as well as surrounding habitat characteristics (Papastamatiou et al. 2018). Ponganis et al. (2000) and Fuiman et al. (2002) demonstrated this, showing that animal-borne cameras could be used to describe the habitat and behavior of both sub-ice and mid-water fish, respectively, during deployments designed to assess taggedspecies foraging behavior. More recently, Thomson et al. (2015) used turtle-borne video to assess seagrass habitat over time; and Jewell et al. (2019) used video imagery from shark-borne tags to quantify prey encounters as a function of habitat type. A few such studies using ancillary video data have therefore been published, and theoretical support for their use has been presented (e.g., Papastamatiou et al. 2018). However, a demonstration and discussion of the potential broad application of ancillary data from animalborne cameras into established analytical survey frameworks is lacking in the growing body of biologging research.

Here, we demonstrate the ability of animal-borne video camera tags (hereafter termed camera tags) to provide data analogous to those derived from established survey techniques for quantitative analysis of marine communities, in situations where location-specific logistics limit available field method options. We illustrate the proof of concept of this approach in relation to traditional survey data, using samples of video data collected along the paths taken by camera-tagged sharks in two distinct eco-systems: (1) a temperate kelp forest surrounding a seal colony, where the risk of human and shark interactions typically precludes scuba diving; and (2) a remote tropical reef system, including the mesophotic zone below typical scientific diving depth limits. Note that the purpose of this work is not to show direct equivalence of methods. Rather, we demonstrate that analogous results and analyses to traditional surveys can be produced within a range of marine habitats and used to usefully inform ecological monitoring and assessment.

\section{Materials and methods}

\section{Temperate kelp forest survey}

We deployed a Customized Animal Tracking Solutions (CATS, Australia) camera tag, consisting of a 12 channel biologging diary tag $(20-40 \mathrm{~Hz}$, tri-axial accelerometers, magnetometers and gyroscopes, depth, temperature and light) coupled with a forward-facing digital video camera $\left(1280 \times 720\right.$ pixel resolution; $30 \mathrm{fps} ; 120^{\circ}$ field of view) on a free-swimming $3.0 \mathrm{~m}$ White shark (Carcharodon carcharias) near a Cape fur seal (Arctocephalus pusillus) colony in the Dyer Island Marine Reserve (location $=34^{\circ} 41.20 \mathrm{~S}, 19^{\circ}$ 25.04 E), near Gansbaai, South Africa in 2014. The primary purpose of this deployment was to understand White shark feeding behavior. We attracted the shark to a research vessel using a combination of macerated fish, fish heads and a seal decoy and attached the camera tag to the shark's dorsal fin using a non-invasive stainless steel fin clamp (Chapple et al. 2015). The camera was programmed to record during daylight hours. The tag was ultimately dislodged from the animal by kelp and was then retrieved. The tagging study was conducted under South African Department of Environmental Affairs permit RES2014/34.

We synchronized tag depth data $( \pm 10 \mathrm{~cm}$ accuracy) to the White shark camera tag video by matching the second the camera entered the water on the video with the second the pressure data recorded submersion. Instantaneous speed can be estimated directly from the tagged animal through trigonometric relationships at steep angles (Gleiss et al. 2011) or in cases where they are equipped with speed sensors, however this unit did not contain an independent speed sensor and we were focused on sections of level swimming, so we assumed a constant cruising speed of $1 \mathrm{~ms}^{-1}$ (Watanabe et al. 2019). We analyzed a $1 \mathrm{~h}$ sample from the $2.3 \mathrm{~h}$ of recorded video to assess key attributes of the kelp-dominated ecosystem (Supplemental Video 1). Using established analytical methods for traditional survey data (i.e., Babcock et al. 1999; Rothman et al. 2010; Krumhansl et al. 2016), we estimated three metrics from the video data, assuming a constant height above the seafloor of $1 \mathrm{~m}$ :

1. The abundance of individual Ecklonia maxima kelp thali (including holdfast, stipe and laminae), along three $50 \mathrm{~m} \times 1 \mathrm{~m}$ transects within continuous sections of forest, noting the kelp's general condition and whether it was canopy-forming, i.e., with laminae reaching the surface (Rothman et al. 2010; Krumhansl et al. 2016); 
2. The percentage cover of six broad-scale underlying habitat types, by visual classification at $1 \mathrm{~m}$ intervals along five $20 \mathrm{~m}$ transects, with habitats consisting of shallow mixed fucoid community, turf field, kelp forest, bare rock, mixed boulder field or sand, following Babcock et al. (1999); and

3. The relative density and location of giant kelp (high density when present and filling $\geq 50 \%$ of the available frame, and low density otherwise).

Dead-reckoned pseudo location tracks were calculated in the software Framework 4 (Walker et al. 2015) through a two-step process first introduced by Wilson et al. (2007). First, heading (i.e., head yaw angle) was calculated using acceleration and magnetometer data and then combined with a fixed estimate of speed $\left(1 \mathrm{~ms}^{-1}\right)$ to compute the pseudo-tracks. A total track length of $\sim 3600 \mathrm{~m}$ was generated from analysis of a one-hour section of video (i.e., $3600 \mathrm{~s} \times 1 \mathrm{~ms}^{-1}$ ). Due to the accumulation of errors from the estimates of heading and speed over the course of the deadreckoned track, the track was used to visualise short-term movements and generate estimates of horizontal positions of the shark. Although additional reference data would be needed to estimate precise geographical positions along the track (Wilson et al. 2007; Walker et al. 2015; Andrzejaczek et al. 2018), we used the tag deployment and retrieval locations as anchor points to overlay the pseudo track on a Google Earth satellite image. This was used to estimate the extents of the kelp forest and the locations of commercially or functionally important indicator species recorded during video analysis, including the Cape rock lobster (Jasus lalandii), the Cape urchin (Parechinus angulosus), the African penguin (Spheniscus demersus), and the Cape fur seal, following Blamey et al. (2010).

Total kelp biomass for canopy-forming sections of habitat was estimated using predicted total sporophyte weight $\left(\mathrm{kg} \mathrm{m}^{-2}\right)$ estimates from Rothman et al. (2010), and average surface-reaching density of E. maxima $\left(\mathrm{m}^{-2}\right)$ assessed from the video footage.

\section{Tropical reef survey}

The CATS camera tag described above was deployed on a $152 \mathrm{~cm}$ total length Grey Reef shark (Carcharhinus amblyrhynchos) in 2014 near Ile Boddam, Salomon Atoll in the Chagos Archipelago $\left(05^{\circ} 22.421 \mathrm{~S}, 72^{\circ} 12.699 \mathrm{E}\right)$ to study reef shark behavior. The shark was caught using a hand line with a barbless circle-hook, secured in water alongside the boat, and the tag temporarily attached to the dorsal fin using cable-ties passed through the fin and joined with a galvanic timed-release corrodible link.

To determine if a camera-equipped shark could visually sample the benthic community in a manner consistent with current diver-based methods, we extracted portions of video footage during which the shark moved from shallower to deep areas of the reef at a constant tailbeat frequency (i.e., speed), determined from the accelerometers (Tanaka et al. 2001), and height ( $1 \mathrm{~m})$ above the substrate. Note that constant height was estimated here by visually assessing changes in the distance to the substrate as a diver would while conducting a transect, but may be further refined as computer learning techniques advance (e.g., Kumar et al. 2020). This approximated the protocol used by a diver carrying out a timed-swim transect (Hill and Wilkinson 2004). Five random independent still frames were extracted from each of six sequential $5 \mathrm{~m}$ depth bands $(10 \mathrm{~m}$ to $40 \mathrm{~m})$ to provide data on changes in benthic composition with increasing depth. PAPARA(ZZ)I software (Marcon and Purser 2017) was used to overlay 10 random points within each image (Supplemental Fig. 1). The substrate that lay beneath each point was classified as live coral, recently dead coral, bleached coral, soft coral, algae, crustose coralline red algae or reef substrate. Points classified as live or dead coral were then sub-classified into one of eight major morphological types, relating to carbonate reef accretion potential: arborescent, bushy, columnar, encrusting, foliose, massive, or unattached, following Denis et al. (2017). We estimated percent cover assuming a constant camera height above the reef of $1 \mathrm{~m}$.

We compared results of animal-borne video to benthic data collected by DOV camera methodology. DOV data were obtained from a long-term scientific program (Sheppard et al. 2017), utilizing data collected in 2014 from the closest monitoring site within Salomon Atoll to the location where the Grey Reef shark was tagged; the southern end of Ile Anglaise (05 20.075 S, $\left.72^{\circ} 12.971 \mathrm{E}\right)$. Three depth zones were surveyed which overlapped with the shark camera tag data: 10-15, 15-20, 20-25 m, and percent cover was estimated from 30 images selected from 10 min video sequences at each depth, using 15 points randomly overlaid within each image (Roche et al. 2015).

Forest plots, created using the R Metafor package, were used to show effect sizes for differences between diver-based and shark-based surveys in kelp and reef habitats. Plots are based on log-transformed response ratios of survey means and their deviation (Lajeunesse 2011). Values shown indicate the log 'Ratio of Means' (ROM), with 95\% CI, where CI values crossing ' 0 ' indicate no significant difference in value between surveys. Zero ROM values indicate no substrate values recorded.

The animal-borne video was also analysed using the methodology typically applied to DOV surveys of fish communities (Harvey and Shortis 1995). The biologger deployed had no speed sensor, so based on the shark's assumed cruising speed of $0.55 \mathrm{~ms}^{-1}$ (Ryan et al. 2015), a $90 \mathrm{~s}$ video segment corresponded to the $50 \mathrm{~m}$ transect 
length (i.e., $50 \mathrm{~m} / 0.55 \mathrm{~ms}^{-1}$ ) normally used in DOVs surveys. Eight non-overlapping $90 \mathrm{~s}$ segments were obtained from video samples where the shark was swimming with an approximately constant direction and height above the reef. Each segment was analysed by an experienced analyst using standard logging software (EventMeasure ${ }^{\mathrm{TM}}$, SeaGIS, Australia) to record species identities, counts and encounter times during video review. The maximum number of individuals of a species seen in a single frame of video during analysis of a sample (MaxN; Cappo et al. 2006) was recorded as the relative abundance of that species in that sample. The shark moved between two distinct reef habitats, reef flat and fore reef wall, providing four samples within each habitat. Qualitative assessment of structure and dominant biota were made to classify reef habitats in the two zones.

The number of species and MaxN sample ${ }^{-1}$ were calculated for each habitat type. Histograms of species abundances were produced for each habitat, and non-metric multidimensional scaling (NMDS) was used to visualise community differences between samples and habitats. NMDS was performed using the function metaMDS() in the $\mathrm{R}$ package vegan, with a Bray-Curtis dissimilarity measure used to quantify the ecological distance between samples. To investigate the effect of total survey time on observed fish species richness, the total video dataset was subsampled in non-overlapping $10 \mathrm{~s}$ segments. Rarefaction and extrapolation (Chao et al. 2014), using the R package iNEXT, were

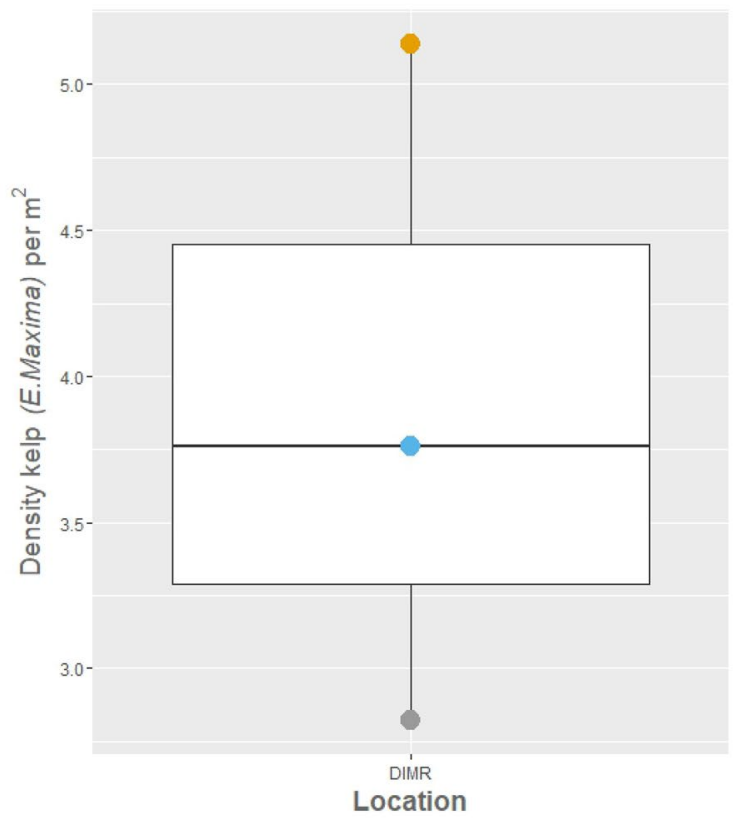

Fig. 1 Density of Ecklonia maxima giant kelp (per $\mathrm{m}^{2}$ ) within the Dyer Island Marine Reserve (South Africa) in 2014. Maximum, minimum, median and interquartile range values shown (left), along with used to first generate an average species accumulation curve as survey time was extended from $10 \mathrm{~s}$ to $12 \mathrm{~min}$, and then estimate the asymptotic species richness if surveys were extended beyond $12 \mathrm{~min}$.

\section{Results}

\section{Temperate kelp forest survey}

Giant kelp density varied from 2.8 to 5.1 thali $\mathrm{m}^{-2}$ $($ mean $=3.9 \pm 0.67)$ along the three surveyed habitat transects (Fig. 1), with the kelp sporophyte thali appearing to still be in the growth phase of their life cycle. The majority of thali had small, non-ragged laminae, with a mixture of predominantly non-canopy-forming structures. The noncanopy-forming thali were typically approximately $1-2 \mathrm{~m}$ from the surface and found within the less dense sections. Kelp was most dense on rocky bedrock substrate, becoming more patchy and dispersed as the substrate transitioned into loose sandy rubble and boulder fields.

The maximum depth was $8.0 \pm 0.21 \mathrm{~m}$ across all transects (Fig. 1) and the shark was estimated, based on the video data, to swim approximately $1 \mathrm{~m}$ off the substrate, giving an approximate maximum substrate depth (and inferred height of canopy-forming thali), of $9 \mathrm{~m}$. The average density of 3.9 kelp thali $\mathrm{m}^{-2}$ equates to an approximate total biomass wet weight of $14.7 \pm 1.76 \mathrm{~kg} \mathrm{~m}^{-2}$ for canopy-forming (i.e.

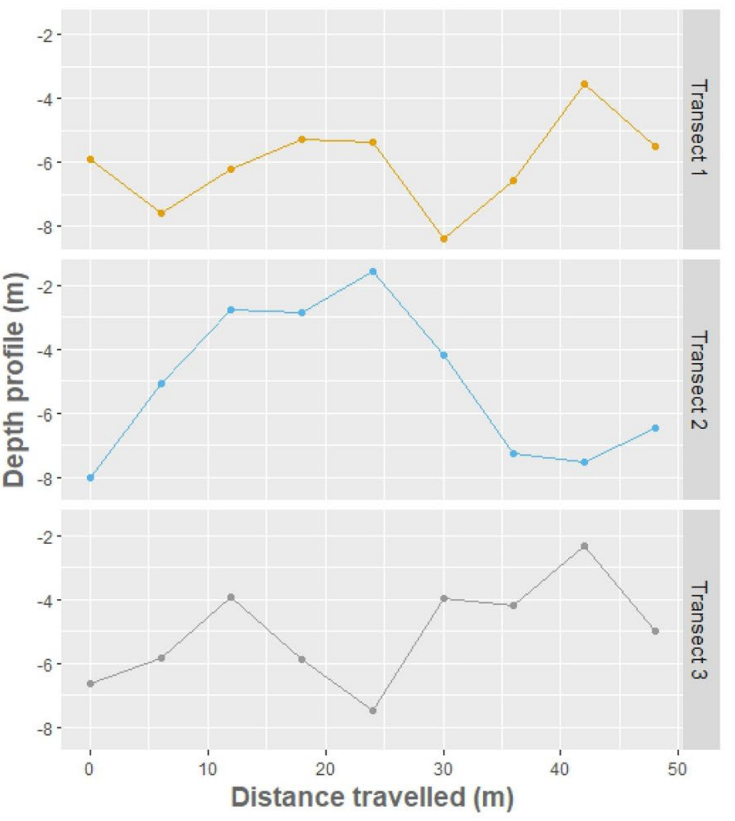

corresponding depth profiles of each $50 \mathrm{~m}$ sample (right). Colours indicate transect number 
surface reaching) kelp habitat (Rothman et al. 2010). These values match well to other records from the Gansbaai coast (Table 1) of $9.22 \pm 3.78 \mathrm{~kg} \mathrm{~m}^{-2}$ in harvested areas in 1992 (Levitt et al. 2002) and $16.1( \pm 2.56) \mathrm{kg} \mathrm{m}^{-2}$ at similar depths in 2010 (Rothman et al. 2010; Supplemental Fig. 2). Substrate classes were patchily distributed across the sampled area, with mixed boulder fields constituting the principal class at 52\%, followed by kelp forest at $25 \%$ (Fig. 2). The pseudo track overlay allowed kelp distribution to be broadly mapped within the reserve over random movement transects (see Jewell et al. 2019, Fig. 2). Five Cape fur seals were observed swimming and refuging in the kelp forest during this period (with their approximate locations noted), with no other prey species recorded (Fig. 3; see Jewell et al. (2019) for further details).

\section{Tropical reef survey}

The Grey Reef shark swam between the surface and a depth of $40.5 \mathrm{~m}$ during the deployment. A total of $159 \mathrm{~min}$ of video data were recorded, during which the reef was clearly observed for $17 \mathrm{~min}(10.7 \%)$. Except for a subset of commonly encountered coral species, identification of hard corals to species-level was not possible due to image resolution and light levels. However, major benthic cover categories could be assigned with high confidence, and hard coral morphologies relevant to reef accretion potential could be identified to $40 \mathrm{~m}$ depth (Fig. 4). There was an overall trend toward increasing hard coral cover with depth, although estimated massive coral abundance was highest $(50 \% \pm 9.3)$ between 10-15 m (Fig. 4). Soft coral cover became evident at depths beyond $25 \mathrm{~m}$, and there was a marked increase in estimated soft coral abundance at depth $(56 \% \pm 5.1$ between 30 and $35 \mathrm{~m}$ and $36 \% \pm 9.1$ between 35 and $40 \mathrm{~m}$ ). Also, notable was the absence of recently dead coral within the deeper zones of 30-35 and 35-40 m.

The traditional diver-operated video survey allowed comparisons within three overlapping depth zones $(10-15$, 15-20, 20-25 m; Supplemental Fig. 2), but not beyond the $25 \mathrm{~m}$ research diving limit in this remote reef area. Foliose

Table 1 Summary and comparison of survey results from analyses of animal-borne video and those from traditional survey methods

\begin{tabular}{|c|c|c|c|c|c|}
\hline Survey location & Survey type & Our study & $\begin{array}{l}\text { Traditional survey } \\
\text { results }\end{array}$ & $\begin{array}{l}\text { Traditional survey } \\
\text { method }\end{array}$ & Citations \\
\hline \multirow[t]{2}{*}{ Kelp } & \multirow[t]{2}{*}{$\begin{array}{l}\text { Standing stock kelpbio- } \\
\text { mass }\end{array}$} & \multirow[t]{2}{*}{$\begin{array}{l}14.7( \pm 1.76) \mathrm{kg} / \mathrm{m}^{2} \text { in } \\
2014\end{array}$} & $\begin{array}{l}9.22( \pm 3.78) \mathrm{kg} / \mathrm{m}^{2} \text { in } \\
1992\end{array}$ & $\begin{array}{l}\text { Destructive removal of } \\
\text { biomass }\end{array}$ & Levitt et al. (2002) \\
\hline & & & $\begin{array}{l}16.1( \pm 2.56) \mathrm{kg} / \mathrm{m}^{2} \text { in } \\
2010\end{array}$ & $\begin{array}{l}\text { Destructive removal of } \\
\text { biomass }\end{array}$ & Rothman et al. (2010) \\
\hline \multirow[t]{23}{*}{ Coral Reef } & \multicolumn{2}{|l|}{ Fish species richness } & & & \\
\hline & Reef Flat & 32 species & $\begin{array}{l}34 \text { total species across } \\
\text { archipelago }\end{array}$ & $\begin{array}{l}138 \text { separate } 60 \text { min } \\
\text { BRUVS surveys }\end{array}$ & Tickler et al. (2017) \\
\hline & Reef Wall & 26 species & & & \\
\hline & \multicolumn{2}{|l|}{ Benthic assessment } & & & \\
\hline & \multicolumn{2}{|l|}{ Foliose Coral } & & & \\
\hline & $10-15 \mathrm{~m}$ & $0.00( \pm 0.00) \%$ & $1.56( \pm 0.69) \%$ & Diver Video Survey & Roche unpublished data \\
\hline & $15-20 \mathrm{~m}$ & $4.00( \pm 2.45) \%$ & $3.11( \pm 1.18) \%$ & & \\
\hline & $20-25 \mathrm{~m}$ & $2.00( \pm 2.00) \%$ & $9.78( \pm 2.45) \%$ & & \\
\hline & \multicolumn{3}{|l|}{ Massive Coral } & & \\
\hline & $10-15 \mathrm{~m}$ & $46.00( \pm 9.27) \%$ & $7.33( \pm 2.48) \%$ & & \\
\hline & $15-20 \mathrm{~m}$ & $24.00( \pm 9.27) \%$ & $6.00( \pm 2.66) \%$ & & \\
\hline & $20-25 \mathrm{~m}$ & $8.00( \pm 5.83) \%$ & $2.22( \pm 1.03) \%$ & & \\
\hline & \multicolumn{3}{|l|}{ Recently dead coral } & & \\
\hline & $10-15 \mathrm{~m}$ & $10.00( \pm 6.32) \%$ & $21.56( \pm 4.55) \%$ & & \\
\hline & $15-20 \mathrm{~m}$ & $4.00( \pm 4.00) \%$ & $11.11( \pm 2.86) \%$ & & \\
\hline & $20-25 \mathrm{~m}$ & $30.00( \pm 5.48) \%$ & $4.00( \pm 1.83) \%$ & & \\
\hline & \multicolumn{3}{|l|}{ Soft Coral } & & \\
\hline & $10-15 \mathrm{~m}$ & $4.00( \pm 4.00) \%$ & $2.89( \pm 1.09) \%$ & & \\
\hline & $15-20 \mathrm{~m}$ & $0.00( \pm 0.00) \%$ & $4.22( \pm 1.30) \%$ & & \\
\hline & \multicolumn{3}{|l|}{ Tabular coral } & & \\
\hline & $10-15 \mathrm{~m}$ & $6.00( \pm 4.00) \%$ & $13.11( \pm 4.54) \%$ & & \\
\hline & $15-20 \mathrm{~m}$ & $2.00( \pm 2.00) \%$ & $6.00( \pm 2.38) \%$ & & \\
\hline & $20-25 \mathrm{~m}$ & $24.00( \pm 8.72) \%$ & $0.44( \pm 0.31) \%$ & & \\
\hline
\end{tabular}


Fig. 2 Percentage cover of six broad-scale habitat classes $(\mathrm{BR}=$ Bare rock, $\mathrm{KF}=$ Kelp forest, $\mathrm{MBF}=$ Mixed Boulder Field, $\mathrm{S}=$ Sand, $\mathrm{SMF}=$ Shallow Mixed Fucoid community, $\mathrm{TF}=$ Turf Field), surveyed along five $(20 \mathrm{~m})$ transects within the Dyer Island Marine Reserve (South Africa) in 2014

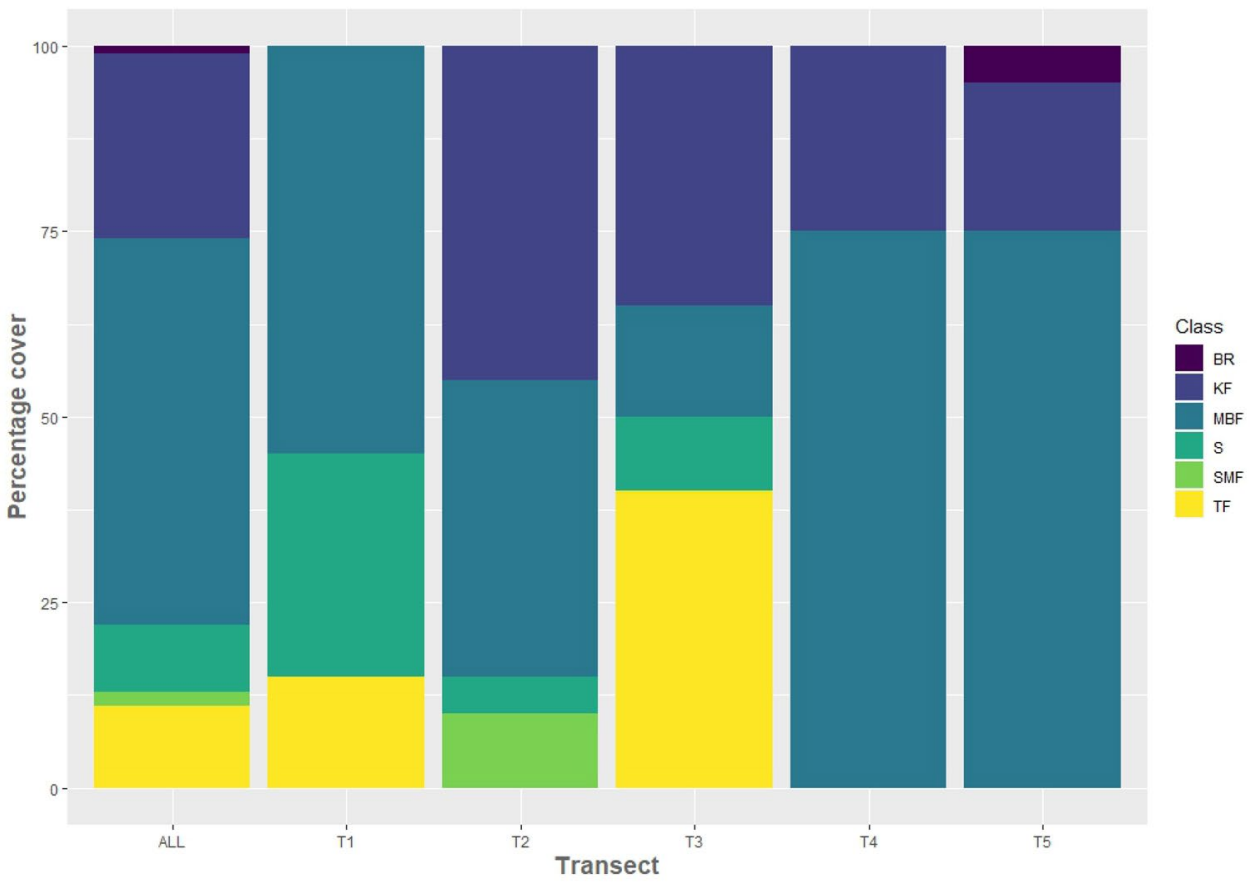

Fig. 3 Approximated pseudo track of a white shark overlayed with satellite imagery within the Dyer Island Marine Reserve (South Africa) from 2014 adapted from Jewell et al. (2019), with red showing the $50 \mathrm{~m}$ transect areas used in analysis and orange circles showing interactions with at least five Cape Fur Seals. The pseudo track here only represents approximate position and is used as a general reference of location, as specific positional information from a pseudo track requires additional positional data Jewell et al. (2019)

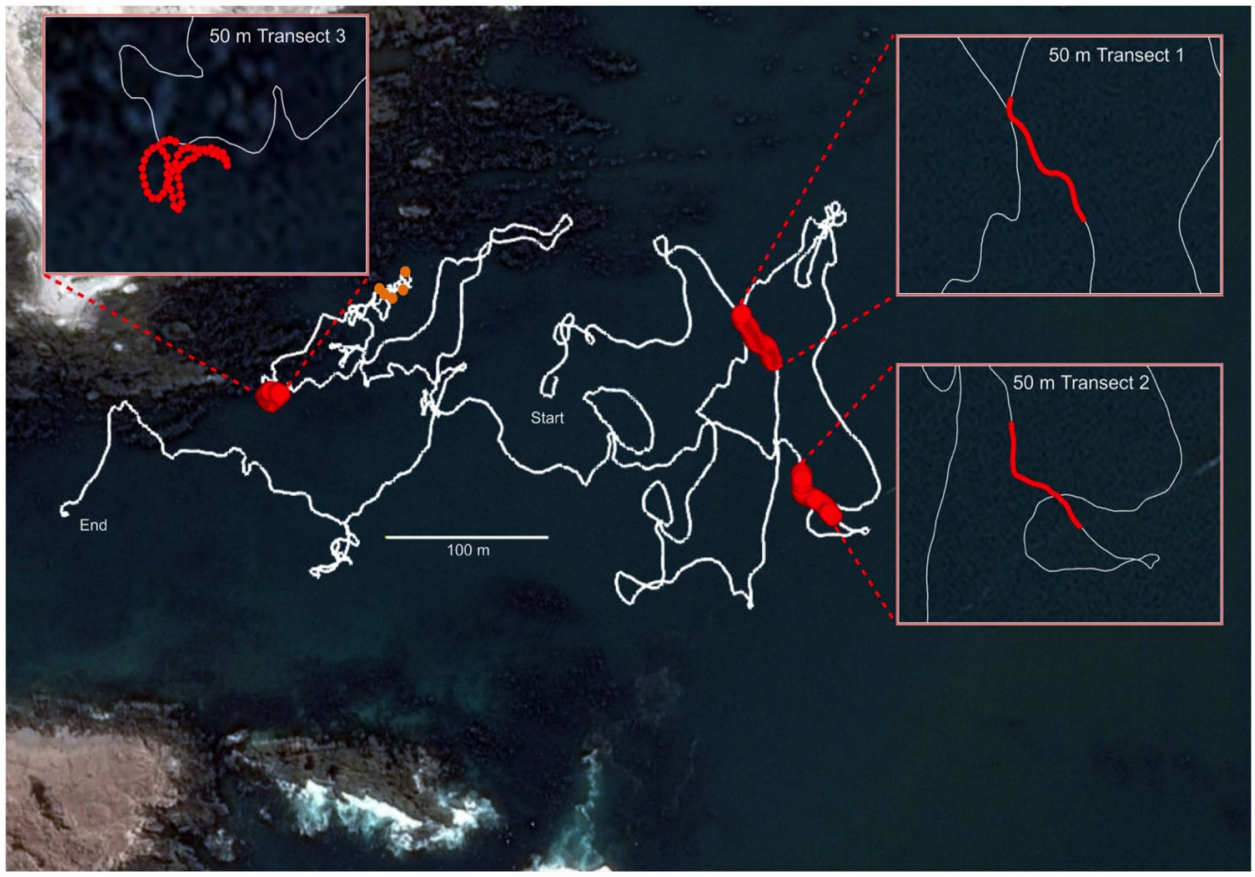

coral was similar between the two methods at $10-15$ and 15-20 $\mathrm{m}$, but higher within the diver video survey at $20-25 \mathrm{~m}(9.78 \pm 2.45$ vs. $2.00 \pm 2.00 \%)$. Massive coral was considerably higher within camera tag than diver video collected data at all depth ranges. Coral classified as recently dead was found to be higher in diver video data at 10-15 and $15-20 \mathrm{~m}$, but higher in camera tag data at $20-25 \mathrm{~m}$. Soft coral was within the margin of error between the two methods, but slightly higher within the diver collected dataset at
$15-20$ and $20-25 \mathrm{~m}(4.22 \pm 1.30 \%$ and $3.33 \pm 1.38$ vs. $0 \%$ in camera tag data). Tabular coral was within the margin of error between the two methods at 10-15 and 15-20 m, but considerably greater cover was found within the camera tag

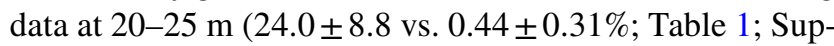
plemental Fig. 2).

Throughout the deployment, the shark moved through two distinct habitat zones. The first habitat was relatively shallow reef flat, characterised by low profile reef interspersed 
Fig. 4 Boxplot of percent benthic coverage of major coral morphological types (Foliose, Massive, and Tabular), recently dead coral and soft coral cover, within $5 \mathrm{~m}$ depth bins from shallow $(10 \mathrm{~m})$ to upper mesophotic $(40 \mathrm{~m})$ depths from a biologging camera tag deployed on a Grey Reef shark off Salomon Atoll, British Indian Ocean Territory. Horizontal bars within the box indicate the median value, and the upper and lower hinges the first and third quartiles respectively. Black horizontal bars on the $x$-axis indicate the absence of the benthic category from a depth range and black dots indicate outlying data points. Red represents data collected by the animal-borne camera and green represents diver-based data

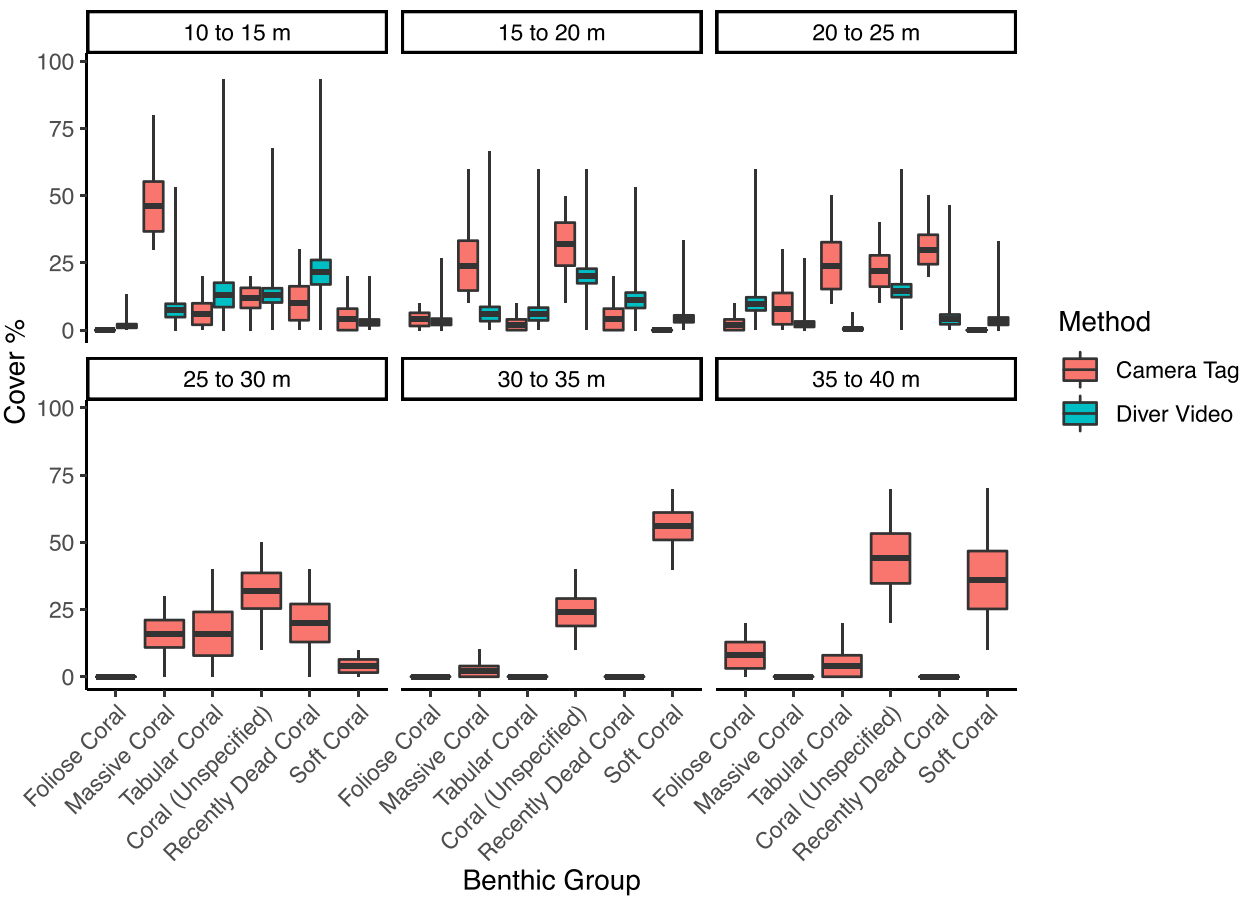

with open hard substrate (Supplemental Fig. 3a). The second habitat type was the fore reef and reef wall. This habitat had high coral cover and higher structural complexity, due in part to a high abundance of gorgonians (Supplemental Fig. 3b). In total, 1277 individual fishes of 45 species from 15 families were observed. The reef flat samples recorded a total of 301 individuals of 32 species from 12 families; the reef wall samples recorded 976 individuals of 26 species from 11 families. Mean species richness was higher on the reef flat, and mean abundance was higher on the reef wall, although differences were not statistically significant due to the small sample size and high variation between samples (Supplemental Fig. 4). These species numbers are similar to the mean value of species (34) estimated across the region from an extensive BRUVS study (Tickler et al. 2017; Table 1).

Of the total species pool, $13(28 \%)$ were common to both habitats, but with marked differences in species abundance (Fig. 5). Analysis of community composition confirmed the two reef habitat types surveyed to have distinct fish communities, with little overlap (Supplemental Fig. 5). Detritivorous surgeonfish (Ctenochaetus striatus) and damselfish (Chromis opercularis) were associated with the reef flat habitat, whereas schooling planktivores (e.g. Acanthurus thompsoni, Naso unicornis, Pseudanthias squamipinnis and Caesio lunaris) were more abundant on the reef wall.

Rarefaction and extrapolation of accumulated species richness across all video samples analysed suggested that despite limited total sampling time (12 min), the shark-based survey had observed $80 \%$ of the expected species pool, and that a sample time of 25 min or more would be sufficient to record the remaining unobserved species (Fig. 6).

\section{Discussion}

Marine ecosystems are challenging to observe and many lack sufficient data to enable detailed understanding of their ecological dynamics or community composition (Richardson and Poloczanska 2008). Here, we provide two examples that demonstrate the potential of animal-borne cameras to expand the availability of survey data through opportunistic collection, particularly in difficult to access locations. Despite the benthic and visual census-like survey data not being the primary focus of these deployments, we have shown how these data can be usefully analysed from animal-borne footage using established techniques developed for DOV surveys, and to yield analogous results (Table 1; Supplemental Fig. 2). Such animal-borne video data can be especially valuable in situations, such as those demonstrated here, where depth, remoteness or risk, limit traditional survey methods.

We suggest that the use of animal-borne videos may be effective when more conventional methods are not available, or to increase the available data pool for difficult to access localities; we do not suggest they replace rigorously designed survey and monitoring programs within marine environments but rather complement monitoring programs. These methods may also be valuable to assess ecological interactions and functional dynamics of systems unsampled through traditional survey methods (for example see Jewell 
Fig. 5 Total recorded abundance $(N)$ by species and habitat type along the reef flat or reef wall

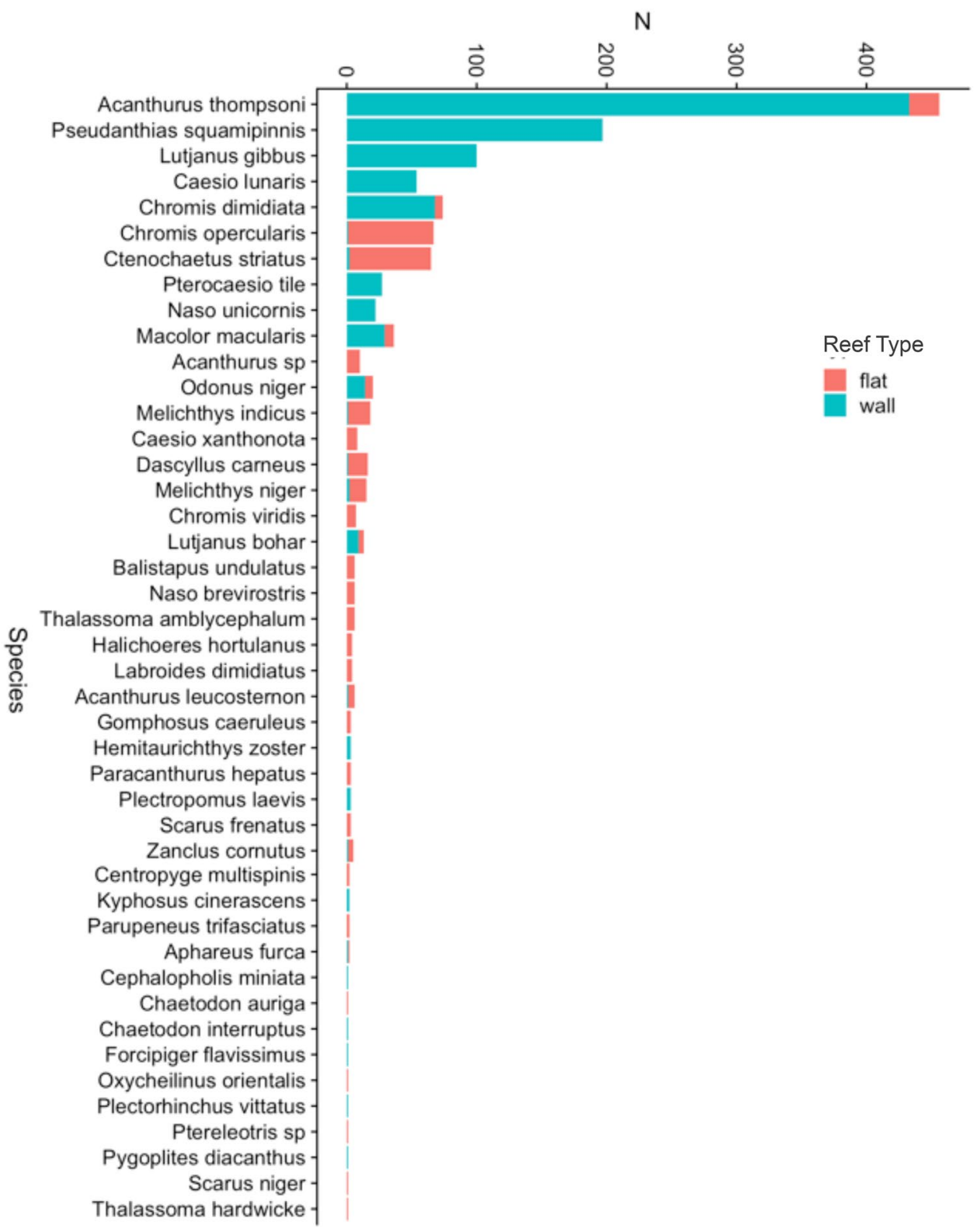

et al. 2019). Additionally, considerations of ancillary data in study design could potentially be valuable or increase their utility, however, the goal of the current study is to explore the use of opportunistic non-target data where the methodology is not driven by the search for these data. Instead, their collection is a valuable addition to the targeted dataset and they can be analysed under the assumptions and caveats of ancillary animal-collected data (e.g., de Vos et al. 2014).

\section{Temperate kelp forest survey}

Increased monitoring of kelp forests is essential for their effective management, as these complex and ecologically important ecosystems are increasingly threatened by local and global impacts, such as climate change, overfishing, invasive species and direct harvest (Krumhansl et al. 2016). In South Africa, we were able to obtain data on kelp biomass density, which matches well to records from previous large-scale extractive surveys of the Gansbaai coast (Levitt et al. 2002; Rothman et al. 2010; Table 1; Supplemental Fig. 2). We were additionally able to ascertain kelp condition and structure in a system where the use of typical diver-based survey techniques is limited by the risk of encounters with large predators foraging in the same environment (Jewell et al. 2019). Alongside the kelp metrics we were able to simultaneously classify and map substrate and additional species distributions; data not available from previous surveys. It should also be noted that all data were collected non-destructively, unlike some 
Fig. 6 Interpolated and extrapolated species richness by cumulative survey time suggests that the limited total sampling time (12 min) had captured $80 \%$ of the expected species, and that a sample time of 25 min or more would approach the asymptote of the species accumulation curve

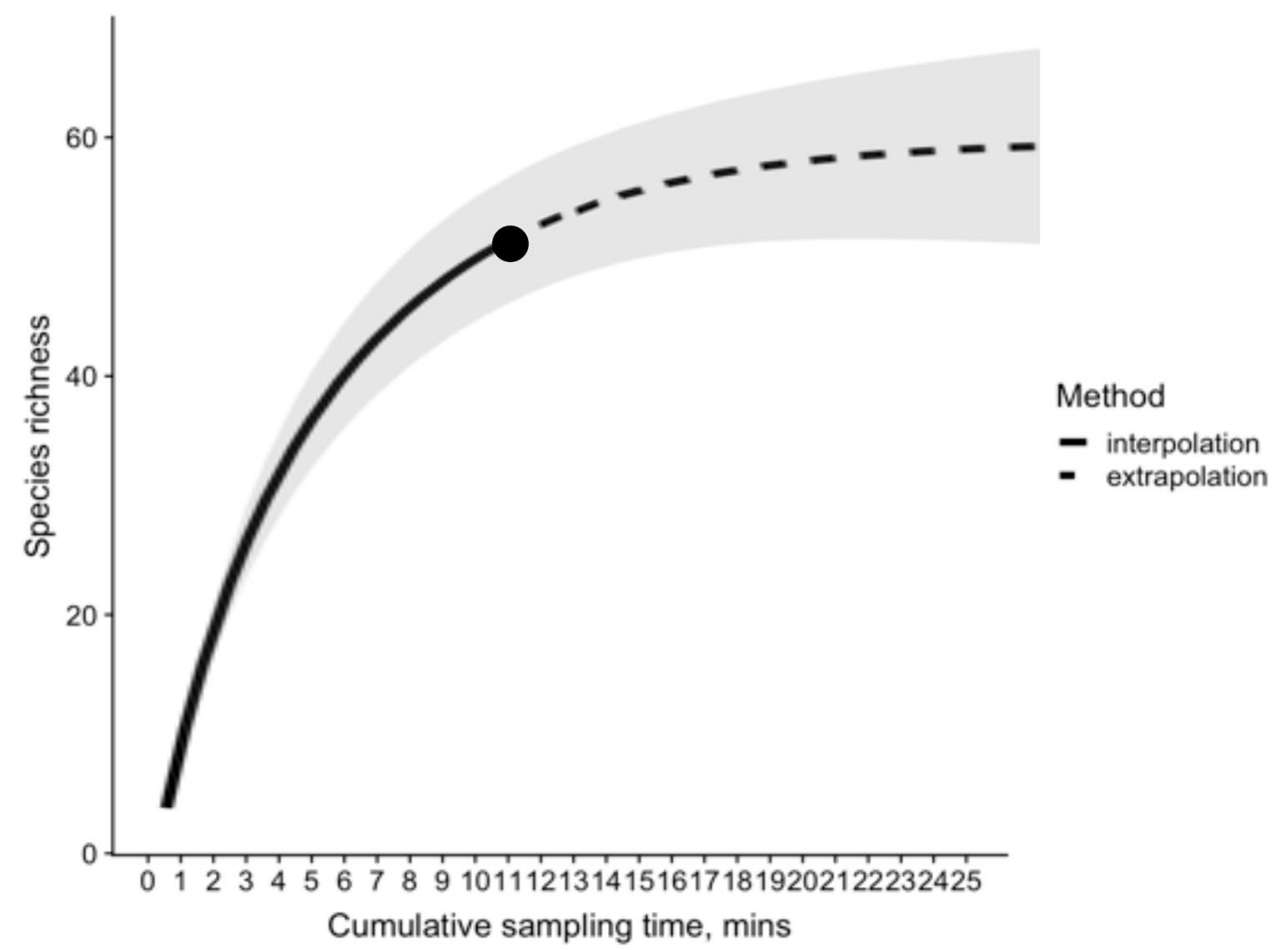

traditional surveys, and leave an archival video resource for future analysis or validation.

\section{Tropical reef survey}

Despite mesophotic reefs being ecologically distinct from shallower reefs, meaning that their condition cannot be extrapolated from existing shallow-water surveys (Rocha et al. 2018), data on benthic coral reef composition from depths below $30 \mathrm{~m}$ are extremely rare, particularly for remote locations such as the Chagos Archipelago (Fig. 4). The general pattern of increased coral cover when reaching mesophotic depths beyond $30 \mathrm{~m}$ found in the present study is consistent with existing knowledge on the mesophotic coral ecosystems of the Chagos Archipelago (Andradi-Brown et al. 2019). The current lack of data on mesophotic reefs across global scales also means that these habitats lack reference points against which to fully assess human impacts on coral reefs (Cinner et al. 2016).

While we show the utility of animal-borne video data to both describe mesophotic reef communities and quantitatively estimate fish community composition, it should be noted that the data were not uniformly in agreement between the DOV and animal-borne video data. For example, animalborne and diver surveys largely agreed in terms of substrate composition, with the majority of reef substrate categories falling within $95 \%$ CI of one-another across depths, though some did vary significantly (Supplemental Fig. 2). However, we would not expect complete agreement across all surveys; the surveys were not conducted in the exact same locations or times and reefs can be highly variable over short spatial and temporal scales (for example Hernández-Fernández et al. 2019). Though this would be problematic for survey assessment frameworks which are dependent on repeated surveys of the same areas, many frameworks utilize haphazard or random sampling (Lewis 2004; Smith et al. 2017), which would be more appropriate for these data.

Again, the purpose of this work was not to show direct equivalence of results from each method, as natural temporal and spatial variability on these dynamic systems makes this goal unrealistic. Instead, we aim to have illustrated here that the data outputs are broadly analogous in terms of the type and quality of metrics attainable and these data can be incorporated in established monitoring and assessment frameworks. As such, the analogous metrics we obtained here include: kelp density, condition, and location; percentage cover of coral reef, broad-scale benthic substrate and growth form; and abundance of reef fish to species or genera level.

\section{Additional considerations}

While illustrating the value of animal-borne video for surveys, we acknowledge that, like any survey technique, there are limitations and assumptions inherent in acquiring survey data using animal-borne video. However, we feel in many cases these considerations can be specifically addressed or can, in some cases, add power to existing datasets. For example, animals carrying 
cameras are free-swimming and may not provide a true random sample of the marine system, as they are likely to associate with certain habitats. Therefore, data from an animal-borne camera can perhaps best be categorised as 'haphazard' (sensu Lewis 2004) rather than random, and are thus similar to sampling methods within large proportions of the ecological literature (Lewis 2004; Smith et al. 2017). Occasionally these data can be even more informative than data obtained from structured surveys, if, for example, animals swim over structurally complex sites in marginal habitats that are often neglected by researchers (Lewis 2004). Pairing of video data with estimated positions may also allow animal-borne camera surveys to be subsampled to achieve a degree of spatial randomization. Although it is difficult to estimate the exact location of animals underwater, pseudo-tracks created from the biologging data and, preferably, refined with geo-reference points (Wilson et al. 2007) can provide an approximate position of the animal and associated habitat (Supplemental Fig. 6).

Frameworks have recently been developed to combine opportunistically collected data (with no formal sampling design) with standardised data from formal monitoring programs (Fithian et al. 2015; Giraud et al. 2016). These studies found an improvement in the predictive power of datasets to provide estimates of species abundance when opportunistically collected data are incorporated. Furthermore, these estimates were more reliable than those obtained from either dataset considered in isolation. Thus, whilst the deployment of animal-borne camera tags can be regarded as a haphazard or quasi-random sampling technique, with some inherent biases, they could serve to complement sampling by ecological researchers and improve the accuracy of ecological variable estimation.

Ecological studies of underwater habitat, particularly in remote or deep locations, often lack the preliminary data needed to provide insight on the spatial distribution and variability of the target habitat, necessary for designing effective sampling regimes due to time and cost constraints. Animalborne cameras could therefore provide pilot data for monitoring programs. These data can refine sampling strata or efforts to determine the number of samples required for monitoring or hypothesis testing, and there are scenarios where multidisciplinary research teams could benefit from the insights gained from animal-borne video to inform sampling design.

\section{Conclusion}

Animal-borne video data can be a valuable complementary source of data when traditional data are available and even more valuable when they are lacking. Although the biologging literature is dense with studies of targeted-animal data, little is available on the potential broad application, analyses, and value of ancillary collected video data and comparisons to more traditional datasets. Many of the apparent drawbacks of the lack of control in placing a video device on a wild animal can be advantageous when considered within an ecological sampling context, and we believe the full potential of this technique is yet to be realised. As camera technology advances and costs reduce, the feasibility of conducting animal-based surveys within inaccessible environments is likely to improve rapidly, providing additional opportunities to access ancillary data where traditional methods are limited. We present promising analogous data as a proof of concept for the use of animalborne video footage for environmental survey. However, additional data from a range of animal-borne cameras will need to be collected alongside standard survey techniques for each animal group, so that the approach can be adapted and rigorously calibrated with more established methodologies. Animal-borne video offers significant potential for quantitative assessments, increasing the power and efficiency of traditional monitoring programs and filling existing gaps in scientific understanding of these systems.

Supplementary Information The online version contains supplementary material available at https://doi.org/10.1007/s00227-021-03916-w.

Acknowledgements The authors would like to thank J Cornelius, CATS, BCH Cornapple, M/Y VAVA for logistical and vessel support for this project and Marine Futures Lab at UWA for providing software access for video analysis and species validations. Research in South Africa was made possible by the Dyer Island Conservation Trust and Marine Dynamics Shark Tours, Gansbaai and we thank W Chivell, H Otto and others within these organisations. Funding was provided by Fondation Bertarelli, National Geographic and Stanford University.

Author contributions TKC, DT, RCR, DTIB, ACG, ABC conceived and designed the experiment, TKC, DT, AGG, OJDJ, SJJ, RS, BAB, ABC acquired data, TKC, DT, RCR, DTIB, AGG, PEK, OJDJ, SA, $\mathrm{NEH}$, JSP conducted analysis and interpretation of data and TKC, DT, RCR, DTIB, AGG, PEK, OJDJ, SJJ, ABC, SA, BAB, NEH drafted or revised the manuscript. All authors agree to publication of the manuscript and accountability to the aspects of the work they conducted

Data availability statement All video data are available in the Movebank Data Repository (www.datarepository.movebank.org).

\section{Declarations}

Conflict of interest All authors declare they have no conflict of interest.

Ethics statement Research was conducted under permit RES201434 issued by The Department of Environmental Affairs, Republic of South Africa and permission from the British Indian Ocean Territory Administration. All methods were approved under animal care and use protocols from the Max Planck Institute and Stanford University (Protocol 10765).

Open Access This article is licensed under a Creative Commons Attribution 4.0 International License, which permits use, sharing, adaptation, distribution and reproduction in any medium or format, as long as you give appropriate credit to the original author(s) and the source, provide a link to the Creative Commons licence, and indicate if changes 
were made. The images or other third party material in this article are included in the article's Creative Commons licence, unless indicated otherwise in a credit line to the material. If material is not included in the article's Creative Commons licence and your intended use is not permitted by statutory regulation or exceeds the permitted use, you will need to obtain permission directly from the copyright holder. To view a copy of this licence, visit http://creativecommons.org/licenses/by/4.0/.

\section{References}

Andradi-Brown DA, Dinesen Z, Head CE, Tickler DM, Rowlands G, Rogers AD (2019) The Chagos Archipelago. In: Mesophotic coral ecosystems 2019, pp 215-229. Springer, Champaign. doi: https://doi.org/10.1007/978-3-319-92735-0_12

Andrzejaczek S, Gleiss AC, Pattiaratchi CB, Meekan MG (2018) First insights into the fine-scale movements of the Sandbar Shark, Carcharhinus plumbeus. Front Mar Sci. https://doi.org/ 10.3389/fmars.2018.00483

Babcock RC, Kelly S, Shears NT, Walker JW, Willis TJ (1999) Changes in community structure in temperate marine reserves. Mar Ecol Prog Ser 189:125-134. https://doi.org/10.3354/meps1 89125

Bayley DTI, Mogg AOM (2019) Chapter 6-new advances in benthic monitoring technology and methodology. In: Sheppard C (ed) World Seas: an environmental evaluation, 2nd edn. Academic Press, New York, pp 121-132

Bean TP, Greenwood N, Beckett R, Biermann L, Bignell JP, Brant JL, Copp GH, Devlin MJ, Dye S, Feist SW, Fernand L, Foden D, Hyder K, Jenkins CM, van der Kooij J, Kröger S, Kupschus S, Leech C, Leonard KS, Lynam CP, Lyons BP, Maes T, Nicolaus EEM, Malcolm SJ, McIlwaine P, Merchant ND, Paltriguera L, Pearce DJ, Pitois SG, Stebbing PD, Townhill B, Ware S, Williams O, Righton D (2017) A Review of the tools used for marine monitoring in the UK: combining historic and contemporary methods with modeling and socioeconomics to fulfill legislative needs and scientific ambitions. Front Mar Sci. https://doi.org/10.3389/fmars. 2017.00263

Beisiegel K, Darr A, Gogina M, Zettler ML (2017) Benefits and shortcomings in the employment of non-destructive benthic imagery for monitoring of hard-bottom habitats. Mar Pollut Bull 121:1. https://doi.org/10.1016/j.marpolbul.2017.04.009

Blamey LK, Branch GM, Reaugh-Flower KE (2010) Temporal changes in kelp forest benthic communities following an invasion by the rock lobster Jasus lalandii. Afr J Mar Sci 32:481-490. https://doi. org/10.2989/1814232X.2010.538138

Borja Á, Elliott M (2013) Marine monitoring during an economic crisis: the cure is worse than the disease. Mar Pollut Bull 68:1-3. https://doi.org/10.1016/j.marpolbul.2013.01.041

Cappo M, Harvey E, Shortis M (2006) Counting and measuring fish with baited video techniques-an overview. In: Australian Society for Fish Biology Workshop Proceedings. Australian Society for Fish Biology Tasmania, pp 101-114

Chao A, Gotelli NJ, Hsieh TC, Sander EL, Ma KH, Colwell RK, Ellison AM (2014) Rarefaction and extrapolation with Hill numbers: a framework for sampling and estimation in species diversity studies. Ecol Monogr 84:45-67. https://doi.org/10.1890/13-0133.1

Chapple TK, Gleiss AC, Jewell OJD, Wikelski M, Block BA (2015) Tracking sharks without teeth: a non-invasive rigid tag attachment for large predatory sharks. Anim Biotelemetry 3:14. https://doi. org/10.1186/s40317-015-0044-9

Cinner JE, Huchery C, MacNeil MA, Graham NA, McClanahan TR, Maina J, Maire E, Kittinger JN, Hicks CC, Mora C (2016) Bright spots among the world's coral reefs. Nature 535:416
Coffey DM, Holland KN (2015) First autonomous recording of in situ dissolved oxygen from free-ranging fish. Anim Biotelemetry 3:47. https://doi.org/10.1186/s40317-015-0088-x

de Vos L, Götz A, Winker H, Attwood CG (2014) Optimal BRUVs (baited remote underwater video system) survey design for reef fish monitoring in the Stilbaai Marine Protected Area. Afr J Mar Sci 36:1-10. https://doi.org/10.2989/1814232X.2013.873739

Denis V, Ribas-Deulofeu L, Sturaro N, Kuo C-Y, Chen CA (2017) A functional approach to the structural complexity of coral assemblages based on colony morphological features. Sci Rep 7:9849. https://doi.org/10.1038/s41598-017-10334-w

Fithian W, Elith J, Hastie T, Keith DA (2015) Bias correction in species distribution models: pooling survey and collection data for multiple species. Methods Ecol Evol 6:424-438. https://doi.org/ 10.1111/2041-210X.12242

Fuiman L, Davis R, Williams T (2002) Behavior of midwater fishes under the Antarctic ice: observations by a predator. Mar Biol 140:815-822. https://doi.org/10.1007/s00227-001-0752-y

Giraud C, Calenge C, Coron C, Julliard R (2016) Capitalizing on opportunistic data for monitoring relative abundances of species. Biometrics 72:649-658. https://doi.org/10.1111/biom.12431

Gleiss AC, Jorgensen SJ, Liebsch N, Sala JE, Norman B, Hays GC, Quintana F, Grundy E, Campagna C, Trites AW et al (2011) Convergent evolution in locomotory patterns of flying and swimming animals. Nat Commun 2:352

Harvey E, Shortis M (1995) A system for stereo-video measurement of sub-tidal organisms. Mar Technol Soc J 29:10-22

Hernández-Fernández L, González de Zayas R, Weber L, Apprill A, Armenteros M (2019) Small-scale variability dominates benthic coverage and diversity across the Jardines de La Reina. Front Mar Sci, Cuba Coral Reef System. https://doi.org/10.3389/fmars.2019. 00747

Hill JJ, Wilkinson CC (2004) Methods for ecological monitoring of coral reefs: a resource for managers. Australian Institute of Marine Science (AIMS), Townsville

Jewell OJD, Gleiss AC, Jorgensen SJ, Andrzejaczek S, Moxley JH, Beatty SJ, Wikelski M, Block BA, Chapple TK (2019) Cryptic habitat use of white sharks in kelp forest revealed by animal-borne video. Biol Lett 15:20190085. https://doi.org/10.1098/rsbl.2019. 0085

Jones D, Bett B, Wynn R, Masson D (2009) The use of towed camera platforms in deep-water science. Underw Technol 28:41-50. https://doi.org/10.3723/ut.28.041

Krumhansl KA, Okamoto DK, Rassweiler A, Novak M, Bolton JJ, Cavanaugh KC, Connell SD, Johnson CR, Konar B, Ling SD, Micheli F, Norderhaug KM, Pérez-Matus A, Sousa-Pinto I, Reed DC, Salomon AK, Shears NT, Wernberg T, Anderson RJ, Barrett NS, Buschmann AH, Carr MH, Caselle JE, Derrien-Courtel S, Edgar GJ, Edwards M, Estes JA, Goodwin C, Kenner MC, Kushner DJ, Moy FE, Nunn J, Steneck RS, Vásquez J, Watson J, Witman JD, Byrnes JEK (2016) Global patterns of kelp forest change over the past half-century. Proc Natl Acad Sci USA 113:13785-13790. https://doi.org/10.1073/pnas.1606102113

Kumar VR, Hiremath SA, Bach M, Milz S, Witt C, Pinard C, Yogamani S, Mäder P (2020) FisheyeDistanceNet: self-supervised scaleaware distance estimation using monocular fisheye camera for autonomous driving. In: 2020 IEEE international conference on robotics and automation (ICRA), pp 574-581

Lajeunesse MJ (2011) On the meta-analysis of response ratios for studies with correlated and multi-group designs. Ecology 92:2049_ 2055. https://doi.org/10.1890/11-0423.1

Levitt GJ, Anderson RJ, Boothroyd CJT, Kemp FA (2002) The effects of kelp harvesting on its regrowth and the understorey benthic community at Danger Point, South Africa, and a new method of harvesting kelp fronds. Afr J Mar Sci 24:71-85 
Lewis JB (2004) Has random sampling been neglected in coral reef faunal surveys? Coral Reefs 23:192-194

Mallet D, Pelletier D (2014) Underwater video techniques for observing coastal marine biodiversity: a review of sixty years of publications (1952-2012). Fish Res 154:44-62. https://doi.org/10.1016/j. fishres.2014.01.019

Marcon Y, Purser A (2017) PAPARA(ZZ)I: An open-source software interface for annotating photographs of the deep-sea. SoftwareX 6:69-80. https://doi.org/10.1016/j.softx.2017.02.002

McMahon CR, Autret E, Houghton JDR, Lovell P, Myers AE, Hays GC (2005) Animal-borne sensors successfully capture the real-time thermal properties of ocean basins. Limnol Oceanogr Methods 3:392-398. https://doi.org/10.4319/lom.2005.3.392

Papastamatiou YP, Meyer CG, Watanabe YY, Heithaus MR (2018) Animal-borne video cameras and their use to study shark ecology and conservation. In: Carrier J, Heithaus MR, Simpfendorfer CA (eds) Shark research: emerging technologies and applications for the field and laboratory. CRC Press, Boca Raton, FL, pp 83-92

Pinheiro HT, Goodbody-Gringley G, Jessup ME, Shepherd B, Chequer AD, Rocha LA (2016) Upper and lower mesophotic coral reef fish communities evaluated by underwater visual censuses in two Caribbean locations. Coral Reefs 35:139-151

Ponganis PJ, Dam RPV, Marshall G, Knower T, Levenson DH (2000) Sub-ice foraging behavior of emperor penguins. J Exp Biol 203:3275-3278

Rees HL (2009) Guidelines for the study of the epibenthos of subtidal environments. ICES Tech Mar Environ Sci 42:94

Richardson AJ, Poloczanska ES (2008) OCEAN SCIENCE: underresourced, under threat. Science 320:1294-1295. https://doi.org/ 10.1126/science. 1156129

Rocha LA, Pinheiro HT, Shepherd B, Papastamatiou YP, Luiz OJ, Pyle RL, Bongaerts P (2018) Mesophotic coral ecosystems are threatened and ecologically distinct from shallow water reefs. Science 361:281-284. https://doi.org/10.1126/science.aaq1614

Roche RC, Pratchett MS, Carr P, Turner JR, Wagner D, Head C, Sheppard CRC (2015) Localized outbreaks of Acanthaster planci at an isolated and unpopulated reef atoll in the Chagos Archipelago. Mar Biol 162:1695-1704. https://doi.org/10.1007/ s00227-015-2708-7

Rothman MD, Anderson RJ, Bolton JJ, Boothroyd CJT, Kemp F (2010) A simple method for rapid estimation of Ecklonia maxima and Laminaria pallida biomass using floating surface quadrats. Afr J Mar Sci 32:137-143. https://doi.org/10.2989/181423210037149 06

Ryan LA, Meeuwig JJ, Hemmi JM, Collin SP, Hart NS (2015) It is not just size that matters: shark cruising speeds are speciesspecific. Mar Biol 162:1307-1318. https://doi.org/10.1007/ s00227-015-2670-4

Sheppard C, Sheppard A, Mogg A, Bayley D, Dempsey AC, Roache R, Turner J, Purkis S (2017) Coral bleaching and mortality in the
Chagos Archipelago. Atoll Res Bull. https://doi.org/10.5479/si. 0077-5630.613

Simmons SE, Tremblay Y, Costa DP (2009) Pinnipeds as oceantemperature samplers: calibrations, validations, and data quality. Limnol Oceanogr Methods 7:648-656. https://doi.org/10.4319/ lom.2009.7.648

Smith ANH, Anderson MJ, Pawley MDM (2017) Could ecologists be more random? Straightforward alternatives to haphazard spatial sampling. Ecography 40:1251-1255. https://doi.org/10.1111/ ecog.02821

Tanaka H, Takagi Y, Naito Y (2001) Swimming speeds and buoyancy compensation of migrating adult chum salmon Oncorhynchus keta revealed by speed/depth/acceleration data logger. J Exp Biol 204:3895-3904

Teo S, Kudela R, Rais A, Perle C, Costa D, Block B (2009) Estimating chlorophyll profiles from electronic tags deployed on pelagic animals. Aquat Biol 5:195-207. https://doi.org/10.3354/ab00152

Thomson JA, Burkholder DA, Heithaus MR, Fourqurean JW, Fraser MW, Statton J, Kendrick GA (2015) Extreme temperatures, foundation species, and abrupt ecosystem change: an example from an iconic seagrass ecosystem. Glob Change Biol 21:1463-1474. https://doi.org/10.1111/gcb.12694

Tickler DM, Letessier TB, Koldewey HJ, Meeuwig JJ (2017) Drivers of abundance and spatial distribution of reef-associated sharks in an isolated atoll reef system. PLoS ONE. https://doi.org/10.1371/ journal.pone. 0177374

Walker JS, Jones MW, Laramee RS, Holton MD, Shepard EL, Williams HJ, Scantlebury DM, Marks NJ, Magowan EA, Maguire IE, Bidder OR, Di Virgilio A, Wilson RP (2015) Prying into the intimate secrets of animal lives; software beyond hardware for comprehensive annotation in 'Daily Diary' tags. Mov Ecol 3:29. https://doi.org/10.1186/s40462-015-0056-3

Watanabe YY, Payne NL, Semmens JM, Fox A, Huveneers C (2019) Swimming strategies and energetics of endothermic white sharks during foraging. J Exp Biol. https://doi.org/10.1242/jeb.185603

Wilson RP, Liebsch N, Davies IM, Quintana F, Weimerskirch H, Storch S, Lucke K, Siebert U, Zankl S, Müller G, Zimmer I, Scolaro A, Campagna C, Plötz J, Bornemann H, Teilmann J, McMahon CR (2007) All at sea with animal tracks; methodological and analytical solutions for the resolution of movement. Deep Sea Res Part II Top Stud Oceanogr 54:193-210. https://doi.org/10.1016/j.dsr2. 2006.11.017

Publisher's Note Springer Nature remains neutral with regard to jurisdictional claims in published maps and institutional affiliations.

\section{Authors and Affiliations}

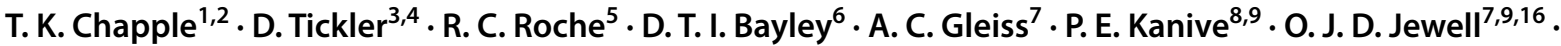
S. J. Jorgensen ${ }^{9,15} \cdot$ R. Schallert ${ }^{2} \cdot$ A. B. Carlisle ${ }^{10} \cdot$ J. Sannassy Pilly ${ }^{5} \cdot$ S. Andrzejaczek ${ }^{2,11} \cdot$ M. Wikelski $^{12,13}$. N. E. Hussey ${ }^{14}$ - B. A. Block ${ }^{2}$

1 Coastal Oregon Marine Experiment Station, Oregon State University, Newport, OR 97365, USA

2 Hopkins Marine Station, Stanford University, Pacific Grove, CA 93950, USA
3 School of Biological Sciences, Marine Futures Laboratory, The Oceans Institute, University of Western Australia, Crawley, Perth, WA 6009, Australia

4 Minderoo Foundation, Dalkeith, WA 6009, Australia

5 School of Ocean Sciences, Bangor University, Anglesey LL59 5AB, UK 
6 Centre for Biodiversity and Environment Research, University College London, London WC1E 6DH, UK

7 Centre for Sustainable Aquatic Ecosystems, Harry Butler Institute, Murdoch University, Murdoch, WA 6150, Australia

8 Department of Ecology, Montana State University, Bozeman, MT 59717, USA

9 Monterey Bay Aquarium, Monterey, CA 93940, USA

10 School of Marine Science and Policy, University of Delaware, Lewes, DE 19958, USA

11 The Australian Institute of Marine Science, Crawley, WA 6009, Australia
12 Max Planck Institute of Animal Behavior, 78315 Radolfzell, Germany

13 Centre for the Advanced Study of Collective Behaviour, University of Konstanz, 78457 Konstanz, Germany

14 Integrative Biology, University of Windsor, 401 Sunset Avenue, Windsor, ON N9B 3P4, Canada

15 Institute of Marine Sciences, University of California, Santa Cruz 95060, Canada

16 Dyer Island Conservation Trust, Kleinbaai, WC 7220, South Africa 